\title{
HUBUNGAN PENATALAKSANAAN PEMBERIAN CAIRAN DIRUMAH DENGAN TINGKAT DEHIDRASI PADA BALITA YANG MENGALAMI DIARE
}

\author{
Zubaidah, $\mathbf{H j}^{1}$,. Maria, Insana ${ }^{2}$ \\ 12 Dosen Sekolah Tinggi Ilmu Kesehatan Intan Martapura, 71213, Indonesia \\ Email : maria.insana82@gmail.com
}

\begin{abstract}
ABSTRAK
Latar Belakang : Penyebab utama kematian diare adalah dehidrasi akibat kehilangan cairan dan elektrolit melalui feses, Penatalaksanaan penyakit diare yaitu dengan cara pemberianterapi cairan yang adekuat untuk mencegah terjadinyadampak lebih lanjut dari diare yaitu anak akan mengalami dehidrasi. Tujuan penelitian untuk mengetahui hubungan penatalaksanaan pemberian cairan dirumah dengan tingkat dehidrasi pada balita yang mengalami diare.

Metode:. Penelitian ini menggunakan metode analitik. Populasi yang digunakan orang tua yang balitanya sedang mengalami diare sebanyak 65 orang. Pengambilan sampel menggunakan tehnik accidental Sampling yaitu 40 responden. Analisis univariat dengan pengumpulan data berupa tabel distribusi frekuensi dan analisis bivariate menggunakan uji Sperman Rank.

Hasil : Hasil uji statistic spearman rho diperoleh nilai $\mathrm{p}=0,000$, yang berarti Ho ditolak dan $\mathrm{Ha}$ diterima terdapat hubungan antara penatalaksanaan pemberian cairan dirumah dengan tingkat dehidrasi. Mayoritas responden dapat melakukan penatalaksanaanpemberian cairan dengan kategori cukup $(62,5 \%)$, tingkat dehidrasi pada balita mayoritas repondenmengalami diare tanpa dehidrasi $(57,5 \%)$.

Kesimpulan: terdapat hubungan antara penatalaksanaan pemberian cairan dirumah dengan tingkat dehidrasi maka diharapkan bagi orang tua agar selalu memberikan cairan yang tepat ketika balita mengalami diare dan apabila kondisi balita tidak segera membaik maka secepatnya balita dibawa kepelayanan kesehatan terdekat.
\end{abstract}

Kata Kunci : Penatalaksanaan pemberian cairan dirumah,balita, diare, tingkat dehidrasi 


\section{PENDAHULUAN}

Salah satu masalah kesehatan balita diIndonesia yang masih sering terjadi adalah diare. Diare merupakan suatu keadaan di mana pada balitafrekuensi buang air besar lebih dari empat kali danpada anak lebih dari tiga kali dengan konsistensifeses yang encer, berwarna hijau atau dapatjuga bercampur lendir dan darah atau lendir saja. Setiap episodenya, diare akan menyebabkan kehilangan nutrisi yang dibutuhkananak untuk tumbuh, sehingga diare merupakan penyebab utama malnutrisi padaanak dan menjadi penyebab kematian kedua pada anak berusia dibawah 5 tahun. (Ngastiyah, 1997 dalam Meivi, 2013). Secara global terdapat dua juta anak meninggal dunia setiap tahunnya karena diare. Pengobatan utama yang harus dilakukan terhadap diare terutama dehidrasi diare adalah rehidrasi dan penggantian air serta elektrolit yang hilang, upaya tersebut dikenal dengan Upaya Rehidrasi Oral (URO). Selain itu menurut Depkes RI dalam mengobati dehidrasi perlu diketahui derajat keparahan dehidrasi karena pengobatannya di golongkan berdasarkan derajat keparahan dehidrasi yaitu tanpa dehidrasi (rencana $\mathrm{A}$ ), dehidrasi ringan/sedang (rencana B), dan dehidrasi berat (rencana C). (Ngastiyah, 1997 dalam Meivi, 2013)

Penyebab utama kematian diare adalah dehidrasiakibat kehilangan cairan dan elektrolit melalui feses. (WHO.2013). Sementara penyebab lainnya adalah disentri, kuranggizi, dan infeksi.Penyebab utama kematian bayi dan anak akibat diare adalah keadaan dehidrasiyang berat. Diare akut pada balita palingbanyak disebabkan oleh infeksi rotavirus.Salah satu penyebab dehidrasi karenaketidaksesuaian penatalaksanaan diare baik di pelayanan kesehatan maupun dirumah. (Widoyono, 2011 dalam Meivi, 2013). Dampak dari diare padabalita lebih berbahaya dari pada orangdewasa, karena komposisi tubuh balita yanglebih banyak mengandung air dibanding orangdewasa, jika terjadi diare balita lebih rentanmengalami dehidrasi dan kompikasi lainyayang dapat merujuk pada malnutrisi ataupunkematian, dampak lain yaitu kegagalan dalampertumbuhan. Diare dapatmenyebabkan dehidrasi sedang dan berat.Sementara itu dehidrasi dapat menyebabkankematian padahal berbagai upaya telahdilakukan untuk menurunkan kejadian diare. Dehidrasi diare yangterjadi dikategorikan menjadi diare tanpa dehidrasi,dehidrasi ringan/sedang, dan berat (Malikah dan Fatimah. 2011).

Salah satu upaya yang dapat dilakukan untuk meluruskan persepsi ibu yang salah tentang pemenuhan cairan adalah dengan pendidikan kesehatan. Pendidikan kesehatan diberikan kepada ibu agar dapat merawat anak dengan baik dalam kondisi sehat maupun sakit. Kebutuhan ibu terhadap pendidikan kesehatan mencakup pengertian dasar tentang penyakit anak, perawatan anak selama dirawat di rumah sakit, dan perawatan lanjutan untuk persiapan pulang (Supartini, 2004).

Pendidikan Kesehatan yang di lakukan oleh ibu akan menjadi efektif dengan adanya proses pengajaran dari perawat karena dengan proses pemberian pengetahuan, dan keterampilan pada ibu maka dapat menurunkan terjadinya komplikasi penyakit (Annalia \& Insana Maria.2019).

Pengembangan dalam memberikan pendidikan kesehatan yang di lakukan oleh perawat harus tetap memperhatikan perilaku Caring dan Comfort dalam pelaksanaannya (Insana Maria, dkk.2019)

\section{METODE PENELITIAN}

Jenis Penelitian ini adalah penelitian analitik, yaitu suatu bentuk penelitian yang bertujuan untuk menguji hipotesis dan mengadakan interpretasi yang lebih mendalam mengenai hubungan antar variabel. Pendekatan yang digunakan adalah observasional yaitu pendekatan penelitian yang mana dalam pengumpulan data tanpa ada intervensi atau perlakuan pada populasi (Nursalam, 2013). Jenis penelitian dalam penelitian ini adalah analitik dengan menggunakan cross sectional. Tempat penelitian dilakukan Puskesmas Karang Intan 2, pada bulan Maret sampai dengan bulan Mei 2018. Populasi dalam penelitian ini adalah semua orang tua balita dan balita yang sedang mengalami diare di puskesmas Karang Intan 2 sejumlah 65 orang. Sampel yang dilakukan penelitian adalah sebagian dari keseluruhan obyek yang diteliti dan dianggap mewakili seluruh populasi (Notoatmodjo S., 2010). Sampel Sampel dalam penelitian ini adalah orang tua balita dan balita yang sedang 
mengalami diare yang kebetulan sedang dibawa ke puskesmas Karang Intan 2 saat dilakukan penelitian. Pengambilan sampel pada penelitian ini dilakukan secara Accidental Sampling.. Instrumen penelitian yang digunakan dalam penelitian ini yaitu Kuesioner Dan lembar observasi sederhana, Prinsip-prinsip dalam etika penelitian ini, yaitu : Informed Consent (lembar persetujuan), anonymity (tanpa nama), confidentiality (kerahasiaan). Data yang telah di kumpulkan selanjutnya dilakukan pengolahan melalui tahap : editing, coding, scoring. Analisa data dalam penelitian ini dilakukan melalui dua tahap, yaitu analisis univariat dengan pengumpulan data berupa tabel distribusi frekuensi dan analisis bivariate menggunakan uji Sperman Rank.

\section{HASIL PENELITIAN}

\section{Hasil Karakteristik Univariate}

Tabel 1

Penatalaksanaan Pemberian Cairan Dirumah Pada Balita Yang Mengalami Diare Di Puskesmas Karang Intan Tahun 2018

\begin{tabular}{|c|l|c|c|}
\hline NO & Pemberian Cairan & F & $\%$ \\
\hline 1. & Baik & 6 & 15 \\
\hline 2. & Cukup & 25 & 63 \\
\hline 3. & Kurang & 9 & 22 \\
\hline & Jumlah & 40 & 100 \\
\hline
\end{tabular}

Sumber : Data primer yang dibuat (2018)

Berdasarkan data diatas menunjukkan bahwa mayoritas responden dapat melakukan penatalaksanaanpemberian cairan dirumah pada balita yang mengalami diare dengan kategori cukup yaitu $63 \%$.

Tabel 2

Tingkat Dehidrasi Pada Balita Yang Mengalami Diare Di Puskesmas Karang Intan 2 Tahun 2018

\begin{tabular}{|c|c|c|c|}
\hline No. & Kategori & $\mathrm{F}$ & $(\%)$ \\
\hline 1. & Tanpa Dehidrasi & 23 & 58 \\
\hline 2. & $\begin{array}{c}\text { Dehidrasi Ringan } \\
\text { - Sedang }\end{array}$ & 17 & 42 \\
\hline 3. & Dehidrasi Berat & 0 & 0 \\
\hline & Jumlah & 40 & 100 \\
\hline
\end{tabular}

Sumber: Data primer yang dibuat (2018)
Berdasarkan data diatas menunjukkan bahwa mayoritas balita mengalami diare tanpa dehidrasi yaitu berjumlah $58 \%$.

Tabel 3

Tabulasi Silang Penatalaksanaan Pemberian Cairan Dengan Tingkat Dehidrasi Pada Balita YangMengalami DiareDi Puskesmas Karang Intan 2 Tahun 2018

\begin{tabular}{|c|c|c|c|c|c|c|c|}
\hline No. & $\begin{array}{c}\text { Penatalaksanaan } \\
\text { pemberian } \\
\text { cairan }\end{array}$ & $\mathrm{T}$ & $\mathrm{P}$ & $\mathrm{D}$ & $\mathrm{P}$ & $\mathrm{T}$ & $\mathrm{P}$ \\
\hline 1. & Baik & 6 & 15 & 0 & 0 & 6 & 15 \\
\hline 2. & Cukup & 17 & 43 & 8 & 20 & 25 & 63 \\
\hline 3. & Kurang & 0 & 0 & 9 & 22 & 9 & 22 \\
\hline & Jumlah & 23 & 58 & 17 & 42 & 40 & 100 \\
\hline
\end{tabular}

Sumber : Data primer yang dibuat (2018)

Keterangan Tabel:

T: Tanpa dehidrasi

D: dehidrasi

P: Persen

T: Total

Berdasarkan tabel diatas menunjukan bahwa orang tua yang melakukan penatalaksanaan pemberian cairan dengan baik pada balita yang mengalami diare menunjukan semua balitanya tidak mengalami dehidrasi yaitu $15 \%$, orang tua yang melakukan penatalaksanaan pemberian cairan dengan cukup pada balita yang mengalami diare menunjukan mayoritas balitanya tidak mengalami dehidrasi sebanyak $43 \%$ sedangkan orang tua yang melakukan penatalaksanaan pemberian cairan dengan kurang pada balita yang mengalami diare menunjukan semua balitanya mengalami dehidrasi ringan-sedang seabanyak $22 \%$.

\section{PEMBAHASAN}

Mayoritas responden dapat melakukan penatalaksanaan pemberian cairan dirumah pada balita yang mengalami diare dengan kategori cukup yaitu 63\%. Penatalaksanaan diare awal di rumah merupakan suatu perilaku terhadap kesehatan. Pengetahuan berpengaruh terhadap praktek baik secara langsung maupun tidak langsung, praktek sesorang dibentuk oleh interaksi individu dengan lingkungan khususnya yang menyangkut pengetahuan terhadap objek. Rendahnya pengetahuan ibu mempengaruhi pola hidup sehat. Pola hidup 
merupakan faktor risiko yang bisa menyebabkan penyakit diare pada bayi dan balita. (Savitri, Endang., 2012) Kurang banyaknya pemahaman ibu tentang informasiinformasi masalah penyakit diare baik secara langsung (penyuluhan-penyuluhan) maupun tidak langsung berupa(informasi berita-berita dari media cetak) dan hal tersebut juga karena adanya pengaruh lingkungan dimana lingkungan tempat penelitian dilaksanakan yaitu di pedesaan, sehingga informasi itu juga didapatkan dari tetangga yang sudah mengerti dan memahami tentang masalah diare. (WHO, 2013).

Berdasarkan data Tabel 2 diatas menunjukkan bahwa mayoritas balita mengalami diare tanpa dehidrasi yaitu berjumlah 58\%. Bayi dan anak-anak lebih mudah mengalami dehidrasi dibanding usia dewasa. Resiko dehidrasi pada anak balita menjadi lebih besar karena komposisi cairan tubuh yang besar dan ketidakmampuan untuk memenuhi kebutuhan sendiri secara bebas. Pada usia lanjut juga lebih rentan mengalami dehidrasi maupun gangguan keseimbangan cairan dan elektrolit dikarenakan penurunan atau gangguan fungsi ginjal atau jantung sehingga hal tersebut dapat meningkatkan keparahan dari dehidrasi. (Price, A. Sylvia, Lorraine Mc. Carty Wilson, 2006), dalam penelitian ini mayoritas balita mengalami diare tanpa dehidrasi, meskipun mayoritas balita berusia 2 tahun yang masih rentan mengalami dehidrasi saat mengalami diare namun ibu telah memberikan air putih, ASI, larutan gula garam, air tajin, air sayur, dan oralit sehingga kejadian dehidrasi pada balita dapat terhindari, bahwa tindakan yang harus dilakukan keluarga jika bayi atau anak menderita diare adalah memberikan bayi atau anak cairan lebih banyak dari biasanya untuk mencegah dehidrasi. (Sutomo, B dan Anggraeni, DY. 2010). Cairan yang dapat diberikan di rumah yaitu ASI, air putih, larutan gula garam, air tajin, air sayur bagi yang sudah mendapat MPASI. (Setiawan, 2006)

Orangtua yang melakukan
penatalaksanaan pemberian cairan dengan baik pada balita yang mengalami diare menunjukan semua balitanya tidak mengalami dehidrasi yaitu $15 \%$, orang tua yang melakukan penatalaksanaan pemberian cairan dengan cukup pada balita yang mengalami diare menunjukan mayoritas balitanya tidak mengalami dehidrasi sebanyak $43 \%$ sedangkan orang tua yang melakukan penatalaksanaan pemberian cairan dengan kurang pada balita yang mengalami diare menunjukan semua balitanya mengalami dehidrasi ringan-sedang seabanyak $22 \%$.

Berdasarkan hasil uji statistic diketahui bahwa nilai sig.(2-tailed) adalah 0,000 nilai ini menunjukan $0,000<0,05$, sebagaimana dasar pengambilan keputusan di atas maka dapat disimpulkan bahwa hipotesis diterima (Ho ditolak) terdapat korelasi yang signifikan pada variable dependent dan variable independent yang berarti bahwa ada hubungan penatalaksanaan pemberian cairan dirumah dengan tingkat dehidrasi pada balita yang mengalami diare di Puskesmas Karang Intan 2 tahun 2018. Selanjutnya, dari tabel di atas diketahui Correlation Coefficient sebesar 0,649 maka nilai ini menandakan hubungan yang tinggi atau kuat antara penatalaksanaan pemberian cairan dirumah dengan tingkat dehidrasi pada balita yang mengalami diare.

Dari uraian di atas dapat di simpulkan bahwa ada hubungan penatalaksanaan pemberian cairan dirumah dengan tingkat dehidrasi pada balita yang mengalami diare di Puskesmas Karang Intan 2 tahun 2018. Tata laksana diare pada balita membutuhkan pengetahuan ibu karena dengan pengetahuan yang baik maka ibu akan melakukan tata laksana diare dengan menggunakan program lintas diare yang diadakan pemerintah. Program Pemerintah untuk mengatasi diare salah satunya dengan mengadakan (Lintas Diare) Lima Langkah Tuntas Diare, yang terdiri dari pemberian oralit osmolaritas rendah untuk mencegah terjadinya dehidrasi, pemberian zinc untuk mengurangi lama dan tingkat keparahan diare, pemberian ASI yang bertujuan untuk memberikan makanan yang kaya nutrisi pada anak dengan diare cair agar 
mendapatkan kembali nafsu makan anak setelah dehidrasi di perbaiki,pemberian antibiotika hanya atas indikasi, pemberian nasihat kepada ibu atau ibu sangat diperlukan (Widjaja, MC. 2002)

\section{KESIMPULAN}

Mayoritas responden dapat melakukan penatalaksanaanpemberian cairan dirumah pada balita yang mengalami diare dengan kategori cukup yaitu 63\%. Dan disimpulkan balita mengalami diare tanpa dehidrasi yaitu berjumlah 58\%. Berdasarkan hasil uji statistic diketahui bahwa nilai sig.(2-tailed) adalah 0,000 nilai ini menunjukan $0,000<0,05$, sebagaimana dasar pengambilan keputusan di atas maka dapat disimpulkan bahwa hipotesis diterima (Ho ditolak) terdapat korelasi yang signifikan pada variable dependent dan variable independent yang berarti bahwa ada hubungan penatalaksanaan pemberian cairan dirumah dengan tingkat dehidrasi pada balita yang mengalami diare di Puskesmas Karang Intan 2 tahun 2018. Selanjutnya, dari tabel di atas diketahui Correlation Coefficient sebesar 0,649 maka nilai ini menandakan hubungan yang tinggi atau kuat antara penatalaksanaan pemberian cairan dirumah dengan tingkat dehidrasi pada balita yang mengalami diare.

\section{AKNOWLEDMENT}

Terimakasih yang sebesarnya kami berikan kepada seluruh perawat dan dokter Pusakesmas Karang Intan2 karena telah di berikan kesempatan untuk melaksanakan penelitian pada Ibu dengan anak yang mengalami Diare, selanjutnya terimakasih yang sebarnya bagi pimpinan STIKES Intan Martapura untuk dana penelitian yang telah di berikan.

\section{DAFTAR PUSTAKA}

Annalia \& Insana Maria. 2019. Hubungan Self-Efficacy Dengan Penatalaksanaan Pencegahan Kekambuhan Hipertensi Di Wilayah Kerja Puskesmas Martapura Ii,
Kalimantan Selatan. Jurnal Keperawatan Suaka Insan. 4 (2) 70-77 2019

Insana Maria, dkk.2019. Perilaku Caring dan Comfort Perawat dalam kegawatdaruratan. Deepublish. Yohyakarta.

Malikah dan Fatimah. 2011. Gambaran Pengetahuan dan Sikap Ibu Dalam Pencegahan dan Penanggulangan Secara Dini Kejadian Diare Pada Balita di Desa Henggarmanah Jatinagor.http://ejournal.stikesmukla.ac. id/index.php/triage/article/download/17 0/167.(03 desember 2017)

Muaris, H. 2012. Lauk Bergizi Untuk Anak Balita. Jakarta: Gramedia Pustaka Utama

Ngastiyah, 1997 dalam Meivi 2013. Perawatan Anak Sakit. Faktor Yang Berhubungan Dengan Kejadian Dehidrasi Diare Pada Balita Di Wilayah Kerja Puskesmas Kalijudan. https://media.neliti.com. (01 desember 2017)

Nursalam. 2013. Konsep dan Penerapan Metodologi Penelitian Ilmu Keperawatan. Salemba Medika. Jakarta

Notoatmodjo S., 2010. Metodologi Penelitian Kesehatan. Jakarta: Rineka Cipta

Savitri, Endang., 2012. P3 Untuk Ananda Di Rumah. Hubungan Tingkat Pengetahuan Ibu tentang Pemberian Larutan Gula Garam Dengan Penanganan Diare Pada Ibu Balita Di Krajan II Secang Magelang.

http://digilib.unisayogya.ac.id ( 02 Desember 2017)

Price, A. Sylvia, Lorraine Mc. Carty Wilson, 2006, Patofisiologi : Konsep Klinis Proses-proses Penyakit, Edisi 6, (terjemahan), Peter Anugrah, EGC, Jakarta 
Setiawan, 2006. Diare Akut karena Infeksi In: Aru W. Sudoyo, BambangSetiyohadi, Idrus Alwi, Marcellus Simadibrata K., Siti Setiati. Editors: BukuAjar Ilmu Penyakit Dalam. Jilid III edisi IV. Jakarta: Pusat PenerbitanDepartemen Ilmu Penyakit Dalam Fakultas Kedokteran Universitas Indonesia

Supartini. 2004. Buku ajar konsep dasar keperawatan anak.http://eprints.umpo.ac.id/1308/1/B AB\%20I.pdf.(02 Desember 2017)

Suriadi, Rita Yuliani., 2006, Asuhan Keperawatan Pada Anak Edisi 2. Jakarta : Sagung setia

Sutomo, B dan Anggraeni, DY. 2010. Menu Sehat Alami untuk Balita dan Batita. PT. Agromedia Pustaka. Jakarta

Uripi, V. 2008. Menu Sehat Untuk Balita. Puspa Swara. Jakarta

WHO.2013. Exclusive Breast Feeding. Dari http://www.who. int/mediacentre/factsheets/fs 330 . (diakses tanggal 28 November 2017)

Widjaja, MC. 2002. Mengatasi Diare dan Keracunan pada Balita. Jakarta:Kawan pustaka

Widoyono, 2011. Penyakit Tropis: Epidemiologi, Penularan, Pencegahan \& Pemberantasannya.Faktor Yang Berhubungan Dengan Kejadian DehidrasiDiare Pada Balita Di Wilayah Kerja Puskesmas Kalijudan.https://media.neliti.com. $\quad(01$ desember 2017) 